Advances in Intelligent Systems and Computing 445

Álvaro Rocha

Ana Maria Correia

Hojjat Adeli

Luis Paulo Reis

Marcelo Mendonça Teixeira Editors

New Advances

in Information

Systems and

Technologies

Volume 2

Q Springer 


\title{
Broadband Access and Digital Divide
}

\author{
João Paulo Ribeiro Pereira \\ School of Technology and Management, Polytechnic Institute of Bragança (IPB) \\ Portugal \\ jprp@ipb.pt
}

\begin{abstract}
It is recognized that there is a disparity between broadband availability in urban and rural areas. The pre-existing telecommunications infrastructure is generally poor and unevenly distributed in favor of urban centers. In most rural areas, low population density and high deployment costs discourage private investments, creating a negative feedback of limited capacity, high prices, and low service demand. Building telecommunications networks in rural areas is costly. Further, in many cases, there is not a good commercial business case for rural deployments. Whereas established and competitive service providers already offer solutions for urban and suburban areas, there is little or no commitment to connect areas that include smaller towns and rural villages. The deployment of access network broadband services on low-competition areas is characterized by low subscriber densities, longer loop lengths, lower duct availability, and consequently higher infrastructure cost compared to high-competition areas.
\end{abstract}

Keywords: Access Networks; NGNs; Broadband Access Networks; Digital Divide.

\section{Introduction}

Communication networks have become a key economic and social infrastructure in OECD economies. The evolution in telecommunication technologies has dramatically changed the dynamics and opportunities in the global economy. The second International Broadband Data Report [1] suggests a positive correlation between broadband adoption and income, population size, and population density. Governments and corporations all over the world recognize that in order to sustain economic growth, substantial changes must be supported [2,3].

However, there is a broad consensus among economists and policymakers concerning two major phenomena: the EU's economic performance has not matched the ambitions formulated in the Lisbon agenda of 2000 and the EU has not reaped the same benefits from modern ICT as the United States. The EU's economic performance has been particularly disappointing, given the strong expansion of the global and US economies in the first years [4]. Policymakers across Europe have acknowledged this situation and reacted with a number of policy initiatives at both the EU- and national level. 


\section{Digital divide}

Access to ICT as a development tool for society is recognized as an important political, economic, and social issue. One of the factors mitigating this digital divide is broadband access, not only in urban areas, but also in rural and developing areas. In this context, local communities and governments are taking various steps to foster economic development in urban and suburban areas and to fight the so-called "digital divide" between well-served urban communities and underserved areas.

Despite the fact that 300 million EU citizens (58\% of total EU population) live in rural, remote and mountainous areas, only $25 \%$ of such areas are covered by fast (download $>30 \mathrm{Mbit} / \mathrm{s}$ ) or ultra-fast broadband (download $>100 \mathrm{Mbit} / \mathrm{s}$ ), as compared to around $70 \%$ coverage in urban areas (source: EC, 2015). Digital divide between urban and rural areas is therefore a fact of life. However, broadband coverage in rural areas has improved in recent years. In comparison to 2010, the rates have doubled in 2013, but the availability of broadband remains uneven.

As previously mentioned, several governments and organizations recognize that there is a disparity between broadband availability in urban and rural areas. Levels of competition among Internet service providers varies among the different OECD member countries and between rural and urban areas within each country [5]. Rural areas are defined as having a scattered population pattern, including small villages or towns. In these areas, network operators traditionally have found it to be less economically attractive to provide broadband access [6]. In most rural areas, low population density and high deployment costs discourage private investments, creating a negative feedback of limited capacity, high prices, and low service demand [7]. The typical view is that there are too few customers per point of presence (POP), making it too expensive for broadband deployment. Whereas established and competitive service providers already offer solutions for urban and suburban areas, there is little or no commitment to connect areas that include smaller towns and rural villages $[8,9]$. The biggest problem for improving the access to broadband is that the private investments are not profitable, due to population dispersion across big areas.

\subsection{The situation in rural and remote areas}

It is believed that the geographical isolation of rural and remote areas is historically a major obstacle for economic development, cultural interchange, and, in general, access to any type of services. With the advances in telecommunication technologies, the lack of infrastructures in rural and remote areas has increased the "digital gap". It is specifically noted that the use of broadband services is concentrated in urban areas.

The low density of the rural and peripheral areas highly spreads and, with long distances to cover in order to be connected to the telecommunication, networks increase the transport infrastructure cost. Due to this latter point, in order to extend broadband networks to rural and remote areas to $100 \%$ of the population, it is not a business for telecommunication operators [10]. The challenge of providing broadband services in rural and remote areas has gained increased attention in recent years. The majority of these areas are not currently covered by cable or DSL. 
Broadband can have a much larger impact on the development of rural areas than any other communications infrastructure, including roads, railways, and telephones [11]. Full broadband coverage is highly important for bridging the digital divide. The digital divide refers to the difference in the ability for people to communicate and utilize e-based business and services relative to their geographical location, living standards, and education level.

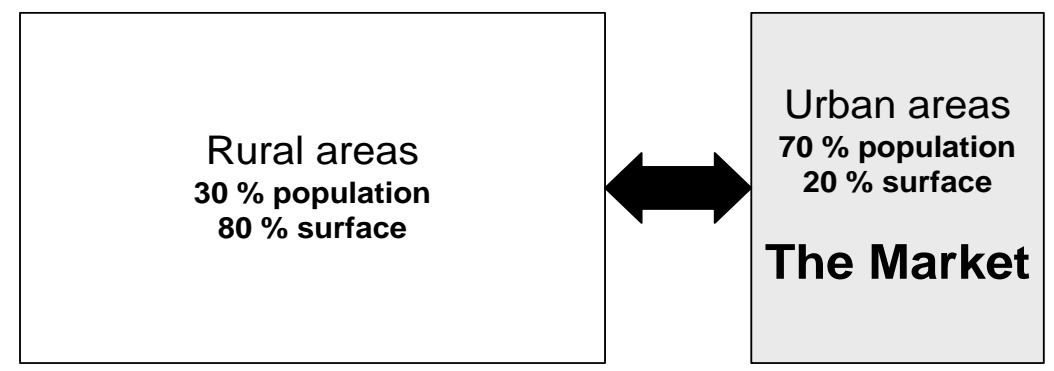

Fig. 1. Rural areas VS Urban areas

Figure 2 illustrates the discrepancies between urban and rural areas, for fixed broadband technologies. Overall coverage of fixed broadband increased by 2 percentage points in the last two years, but there was a remarkable progress in rural areas from $79.9 \%$ in 2011 to $89.8 \%$ in 2013.

Fixed broadband coverage in the EU, 2011-2013

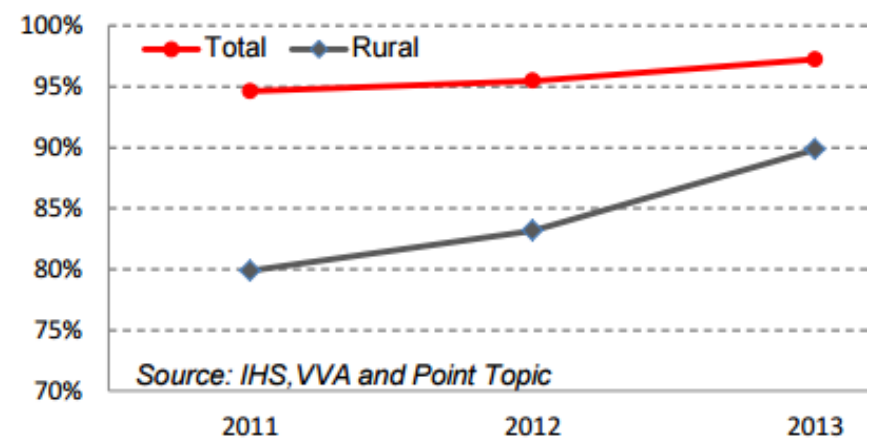

Fig. 2. Fixed broadband coverage in the EU: 2011-13

Figure 3 shows, the penetration discrepancies between rural areas and national levels. The rural areas have deficient coverage limit penetration and the late introduction of broadband in those areas has created further delays in take-up. 


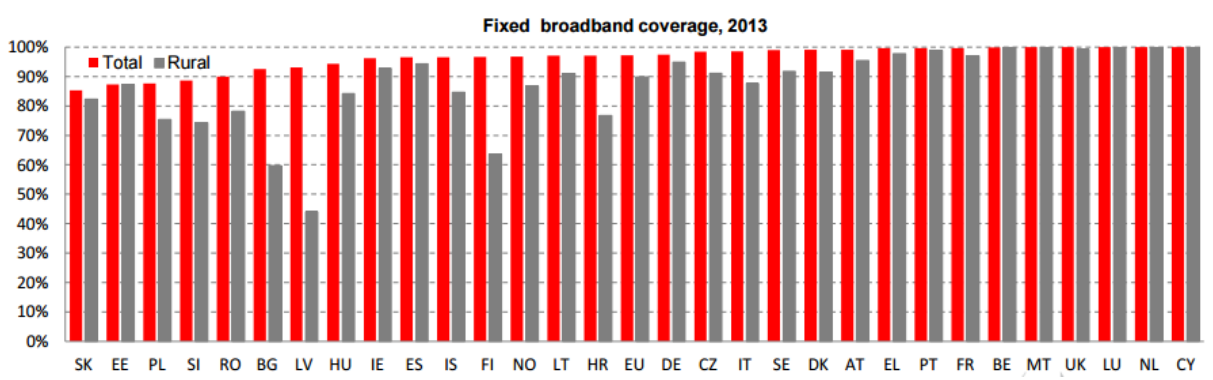

Fig. 3. Fixed broadband coverage: 2013 (Source: IHS and VVA)

Next Generation Access includes VDSL, Cable Docsis 3.0 and FTTP. At the end of 2013, Cable Docsis 3.0 had the largest NGA coverage at $41.2 \%$, followed by VDSL (31.2\%) and FTTP (14.5\%). Developments until 2012 were dominated by the upgrade of cable networks, while VDSL coverage grew by more than $60 \%$ in the last two years. NGA networks are currently very much limited to urban areas: rural coverage is only $18.1 \%$, coming mainly from VDSL [12].

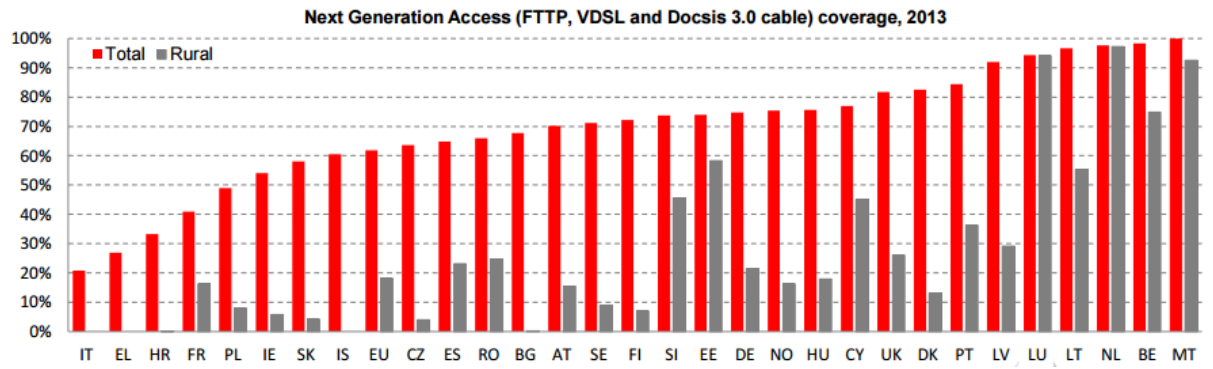

Fig. 4. NGA coverage: 2013 (Source: IHS and VVA)

The lack of telecommunication infrastructure in rural areas is primarily due to the high costs of building "last-mile" networks in the communities. Sparseness of the population, difficult terrain in which to install copper pairs, and insufficient revenues to justify costs are some of the reasons for this limitation. The growth of the Internet and rapid deployment of broadband services in urban cities make rural areas more vulnerable to not receiving access to advanced telecommunication and information services. Therefore, it is possible that the digital gap between the information "haves" and "have nots" will widen. The digital society increased the rapid bandwidth demand, which put pressure on the network. Although national networks are frequently upgraded to cope with this demand, a bottleneck remains over the "last (or first) mile" between the costumer and the first node in the network. Building telecommunications networks in rural areas is costly. In addition, in many cases, there is not a good commercial business case for rural deployments. Then, prices for Internet access in some markets remain high, and users might have a limited choice of broadband providers.

Significant shares of copper wirelines in both rural and urban areas have excessive lengths, which prevents high-capacity communication. In rural areas, long xDSL lines often correspond to the scattered population outside of the densely populated areas. 
Cable operators have extensive coverage in some countries, but their networks are often limited to high- to medium-density housing. As a result, the first 5-10 km wireline access part may be difficult to set up in rural or remote areas. Consequently, alternatives to XDSL must be used to fill the coverage gap. These alternatives are primarily wireless networks, such as BFWA and DTT or DVB-S, with return channels. Forums, such as WiMAX, have demonstrated the possibility of deploying additional wireless networks that are competitive or better than xDSL solutions. In scattered areas, access to fiber backhaul can be difficult to achieve, making wireless technologies, such as satellite or terrestrial radio, an interesting solution, including both point-to-point and point-to-multipoint systems.

As a result, some researchers have begun to question the cost-benefit rationale of extending Internet access to these high-cost, low-income areas. For example, [13] argued that in order to address the informational needs of the rural poor, traditional technologies, such as broadcast radio, provide a more cost-effective alternative. Over the last decade, numerous demonstration projects have been undertaken to demonstrate the benefits of Internet connectivity for a variety of rural development goals. However, long-term sustainability and wider-scale replication are rarely obtained. The reasons are complex, but most researchers point to a combination of poor design and implementation that does not properly account for local conditions, as well as the use of technologies developed for urban markets.

\section{Conclusions}

There has been significant progress toward reaching rural and remote areas with broadband. However, as previously mentioned, rural areas are unlikely to attract new entrants because they are costly to serve and have insufficient demand. Nevertheless, recent developments in wireless technologies are raising new hopes for sustainable Internet diffusion in rural areas of the developing world. These technologies permit drastic reductions in deployment costs, particularly for last-mile connectivity in lowdensity areas. Incumbent providers are conducting trials using WiMAX to provide broadband access services to areas in which it is not economical to upgrade DSL. New wireless technologies make possible an infrastructure development model based on community-shared resources, small-scale investments, and user experimentation.

However, these promising new technologies, such as WiMAX, LTE, and PLC, have not been a major part of these broadband deployments. Cable, DSL, satellite, and various fixed-wireless access technologies are still the technologies supplying Internet access to rural areas. New DSL technologies that increase the distance of data transmission have played an important role in this areas. The dramatic cost reduction of DSL equipment during the last several years and the development of smaller units (e.g., mini or micro DSLAMs) have steadily decreased this threshold, although the backhaul costs are still prohibitive in some areas.

Therefore, wireless solutions will play an important role in connecting these areas, but there will likely be greater demand for high-capacity fiber to reach as widely as possible into these areas in order to feed wireless connections. Results of research show that hybrid architectures that combine the advantages of different wireless or 
wired technologies are central in delivering broadband services to rural areas in a cost-effective manner.

\section{References}

1. FCC: Second International Broadband Data Report. Federal Communications Commission (2011)

2. Pereira, J.P.R.: Effects of NGNs on Market Definition. In: Rocha, Á., Correia, A.M., Wilson, T., Stroetmann, K.A. (eds.) Advances in Information Systems and Technologies, vol. 206, pp. 939-949. Springer Berlin Heidelberg (2013)

3. Langeheine, B.: Broadband access and (minimum) bandwidth for everyone. In: EuropeanCommission (ed.) WIK International Conference. European Comission (2010)

4. Pols, A.: The Role of Information and Communications Technology in Improving Productivity and Economic Growth in Europe: Empirical Evidence and an Industry View of Policy Challenges. In: Tilly, R., Welfens, P., Heise, M. (eds.) 50 Years of EU Economic Dynamics, pp. 183-201. Springer Berlin Heidelberg (2007)

5. OECD: Broadband Growth and Policies in OECD Countries. OECD Publications (2008)

6. Tardy, I., Braten, L., Bichot, G., Settembre, M., Sesena, J.: Hybrid architecture to achieve true broadband access in rural areas. In: BroadBand Europe, pp. 1-6. (2004)

7. Dong, C., Brown, J., Khan, J.Y.: Performance analysis of a distributed 6LoWPAN network for the Smart Grid applications. In: Intelligent Sensors, Sensor Networks and Information Processing (ISSNIP), 2014 IEEE Ninth International Conference on, pp. 1-6. (2014)

8. Boscher, C., Hill, N., Laine, P., Candido, A.: Providing Always-on Broadband Access to Under-served Areas. Alcatel Telecommunications Review 127-132 (2004)

9. Pereira, J.P.R.: Simulation of Competition in NGNs with a Game Theory Model. In: Ramona, T., Gabriel-Miro, M. (eds.) Convergence of Broadband, Broadcast, and Cellular Network Technologies, pp. 216-243. IGI Global, Hershey, PA, USA (2014)

10.Stasiak, M., Glabowski, M., Wisniewski, A., Zwierzykowski, P.: About the Modelling and Dimensioning of Mobile Networks: From GSM to LTE. John Wiley \& Sons Inc, United Kingdom (2011)

11.Cornu, J., Hughes, G.: Digital Divide and Broadband Territorial Coverage. e Europe Advisory Group (2004)

12.EuropeanCommission: Broadband Coverage in Europe 2013. European Comission (2014)

13.Galperin, H.: Wireless Networks and Rural Development: Opportunities for Latin America. Information Technologies and International Development 2, 47-56 (2005) 